We acknowledge the invaluable organisational help of our research secretary, Mrs Valerie Shakespeare, who, together with AD, was supported by a project giant from the Medical Research Council. We also thank Staff Nurse Kwai Foong Low for her help in following up the Chinese families; the staff of the hepatitis laboratory at the Regional Blood Transfusion Centre for screening all the antenatal sera; the laboratory staff at East Birmingham Hospital for viral, chemical, and immunological testing; and all the family doctors, obstetricians, paediatricians, and mothers and their babies for cooperating in our study.

Requests for reprints should be sent to Dr Elizabeth Boxall.

\author{
References \\ ${ }^{1}$ Sherlock, S, Lancet, 1976, 2, 354. \\ 2 Combes, B, et al, Lancet, 1971, 1, 234 \\ ${ }^{3}$ London, W T, New England fournal of Medicine, 1977, 296, 1528. \\ 4 Wright, R, et al, British Medical fournal, 1970, 4, 719. \\ ${ }^{5}$ Kattamis, C A, and Demetrios, D, Pediatrics, 1974, 54, 157. \\ ${ }^{6}$ Schweitzer, I L, et al, Gastroenterology, 1973, 65, 277.
}

' Schweitzer, I L, Proceedings of the National Academy of Sciences, 1975, 270, 287.

${ }^{8}$ Papaevangelou, G, Hoofnagle, J, and Kremastinou, J, Lancet, 1974, 2, 746.

${ }^{9}$ Stevens, C E, et al, New England Fournal of Medicine, 1975, 292, 771.

10 Boxall, E H, Biomedicine, 1977, 26, 12.

${ }^{11}$ Kohler, D F, et al, New England fournal of Medicine, 1974, 291, 1378.

${ }^{12}$ Holzback, R T, American fournal of Medicine, 1976, 61, 367.

${ }^{13}$ Linneman, C C, and Goldberg, S, Lancet, 1974, 2, 155.

${ }_{14}$ Magnius, L O, and Espmark, J A, fournal of Immunology, 1975, 109, 1017.

15 Boxall, E H, and Davies, H, Lancet, 1974, 2, 1513.

${ }^{16}$ Papaevangelou, G, et al, Archives of Disease in Childhood, 1974, 49, 936.

17 Skinhoj, P, Cohn, J, and Bradburne, A F, British Medical fournal, 1975, $1,10$.

${ }^{18}$ Skinhoj, P, et al, American fournal of Diseases in Childhood, 1972, 123, 380.

19 Eddleston, A L W F, Postgraduate Medical fournal, 1974, 50, 348.

${ }^{20}$ Yeung Leiwah, A A C, Lancet, 1971, 2, 470.

${ }^{21}$ Dudley, F J, Giustino, V, and Sherlock, S, British Medical fournal, 1972, है 4, 754 .

2:2 Okada, K, et al, New England fournal of Medicine, 1976, 294, 746.

${ }_{23}$ Palmer Beasley, R, et al, American fournal of Epidemiology, 1977, 705, 94.

${ }^{24}$ Neurath, A R, and Strick, N, Lancet, 1977, 1, 146.

\title{
Dextran and intermittent pneumatic compression in prevention of postoperative deep vein thrombosis: multiunit trial
}

\author{
R C SMITH, R A ELTON, J D ORR, A J L HART, D F GRAHAM, G A G FULLER, \\ J S H RUNDLE, A I S MACPHERSON, C V RUCKLEY
}

British Medical fournal, 1978, 1, 952-954

\section{Summary and conclusions}

Seven general surgical units co-operated in a clinical trial of dextran 70 and pneumatic calf compression alone and in combination in the prevention of ${ }^{125}$ I-fibrinogendetectable deep vein thrombosis in 305 patients.

Both dextran regimens were significantly more effective than pneumatic compression alone. Pulmonary embolism was diagnosed in 14 patients, but there was no significant difference in incidence among the three treatment groups. In patients receiving dextran there was no greater median operative blood loss but there was a significantly greater incidence of postoperative bleeding complications.

\section{Royal Infirmary of Edinburgh, Edinburgh EH3 9YW}

R C SMITH, MB, FRCSED, senior surgical registrar

A J L HART, MB, FRCSED, surgical registrar

G A G FULLER, MB, CHB, registrar

A I S MACPHERSON, CHM, FRCSED, FRSED, consultant surgeon

Medical Computing and Statistics Group, University of Edinburgh R A ELTON, MA, PHD, lecturer in medical statistics

Western General Hospital, Edinburgh, Edinburgh EH4 2XU J S H RUNDLE, MB, FRCSED, surgical registrar C V RUCKLEY, CHM, FRCSED, consultant surgeon

Bangour General Hospital, West Lothian EH52 6LR

D F GRAHAM, MB, FRCSED, surgical registrar

Chalmers Hospital, Edinburgh EH3 9HG

J D ORR, MB, FRCSED, surgical registrar

\section{Introduction}

Most surgeons agree on the need for prophylaxis against thromboembolism in patients undergoing operation but not on the method of choice. Evidence suggests that the most effective prophylaxis in general surgical patients is low-dose subcutaneous heparin..$^{1-4}$ Some surgeons, however, believe that this may cause excessive blood loss during and after operation, and the twice- or thrice-daily injections needed makes it distressing for the patient as well as time-consuming for nursing staff. Thus many centres use dextran infusions or pneumatic calf compression or both as routine methods of prophylaxis, reserving heparin for patients at particular risk.

Use of dextran and pneumatic compression have separately been shown to be effective prophylactic methods. ${ }^{5-11}$ We therefore decided to compare the two, used singly and in combination, to see whether there was any additive effect. Seven general surgical units in four hospitals in the Lothians Area Health Board participated in the trial, which in each unit was supervised by a registrar.

\section{Patients and methods}

Any patient aged over 40 admitted for an operation likely to last more than 30 minutes was considered for inclusion in the trial. Because of low risk, technical problems of scanning, or the surgeon's preference for a different method of prophylaxis patients in the following groups were excluded: those aged below 40; patients undergoing operations on the head and neck or left chest wall, vascular procedures or operations on the legs, and emergency surgery; women taking the "pill"; and patients with a recent history of venous thromboembolism.

For ethical reasons an untreated control group was not included.

Treatment regimens - Patients admitted to the trial were allocated at random to the three treatment regimens by means of sealed envelopes, numbers being restricted to ensure that the groups were of comparable 
size. One group received $500 \mathrm{ml}$ dextran 70 in saline over at least 30 minutes beginning with the induction of anaesthesia, a further $500 \mathrm{ml}$ being given over four hours within eight hours of completing the operation; a second group received intermittent pneumatic compression with the BOC-Roberts pump during the operation; and a third group received both treatments.

Diagnosis of deep vein thrombosis (DVT)-All patients were monitored with the ${ }^{12: 5}$ I-fibrinogen uptake test. ${ }^{12}$ Leg scanning was begun the day before operation and continued on alternate days until day 7 or discharge from hospital. If the scan appeared to become positive daily scanning was performed. A scan was regarded as positive when there was a $20 \%$ rise in activity persisting for 24 hours or more at any point relative to the same point on the previous scan or compared with the corresponding point on the other leg. ${ }^{6}$ On completion of the trial the scans were assessed "blind"-that is, without reference to the patient or method of prophylaxis-by two of us (RCS and CVR).

\section{Results}

Altogether 305 patients were entered into the trial, of whom 12 were subsequently excluded; reasons were pump failure (1 case), leggings removed inadvertently (1), excess bleeding with dextran (7), allergy to dextran (1), and dextran "contraindicated" (2). Of the remaining 293 patients, 99 were treated with dextran, 96 with calf pumps, and 98 with both methods. Mean age was $60 \pm$ SD 12 years, and 133 were men and 160 women. Twelve had previously had DVT, two had had pulmonary emboli, and 55 had varicose veins. In 229 patients the operation was for a benign condition, in 38 it was potentially curative for malignant disease, and in 26 it was merely palliative. There was no significant difference in the distribution of risk factors among the three groups.

Incidence of $D V T$ - In four patients scanning was technically unsatisfactory. Of the other $289,75(26 \%)$ developed positive leg scans (table I), two-thirds of which occurred within three days of operation. Only $17(23 \%)$ of the patients with positive scans had clinical signs. There was no significant difference in the incidence of DVT among the seven units, and no significant difference among the groups in the time of onset of the DVT, the extent of the DVT as judged by the number of points with increased counts, or the incidence of DVT in the thighs. DVT was significantly less common in patients who had received dextran $(22 \%)$ and dextran plus pneumatic compression $(19 \%)$ than in patients given pneumatic compression alone $(38 \%$ ) (table I).

Pulmonary embolism-Minor pulmonary embolism was diagnosed clinically in 14 patients, and in 11 a perfusion lung scan was performed,

TABLE I-Incidences of DVT (positive leg scans) in the three treatment groups

\begin{tabular}{l|c|c|c|c}
\hline & $\begin{array}{c}\text { Dextran } \\
\text { alone }\end{array}$ & $\begin{array}{c}\text { Compression } \\
\text { alone }\end{array}$ & $\begin{array}{c}\text { Dextran and } \\
\text { compression }\end{array}$ & Total \\
\cline { 1 - 3 } $\begin{array}{c}\text { No of patients in } \\
\text { treatment group .. }\end{array}$ & 97 & 95 & 97 & 289 \\
$\begin{array}{c}\text { No (".,) with positive } \\
\text { scans }\end{array}$ & $21(22)$ & $36(38)$ & $18(19)$ & $75(26)$ \\
\hline
\end{tabular}

Statistical evaluation-Overall: $\chi^{2}=10 \cdot 75 ; \mathrm{P}=0.01$. Dextran $v$ compression: $x^{2}=$ 5.31; $\mathrm{P}<0.05$. Dextran $v$ dextran and compression: $\chi^{2}=0 \cdot 13$; NS. Compression $v$ $5 \cdot 31 ; \mathrm{P}<0 \cdot 05$. Dextran $v$ dextran and compres.
dextran and compression: $\chi^{2}=7 \cdot 97 ; \mathrm{P}<0.01$.

TABLE II-Incidences of DVT in patients with benign and malignant disease in the three treatment groups

\begin{tabular}{|c|c|c|c|c|}
\hline & $\begin{array}{l}\text { Dextran } \\
\text { alone }\end{array}$ & $\begin{array}{c}\text { Compression } \\
\text { alone }\end{array}$ & $\begin{array}{l}\text { Dextran and } \\
\text { compression }\end{array}$ & Total \\
\hline \multicolumn{5}{|c|}{ Benign disease } \\
\hline $\begin{array}{l}\text { No without DVT } \\
\text { No }(" \text { "i) with DVT } \\
.\end{array}$ & $\begin{array}{l}57 \\
12(17)\end{array}$ & $\begin{array}{l}48 \\
27(36)\end{array}$ & $\begin{array}{l}67 \\
17(20)\end{array}$ & $\begin{array}{r}172 \\
56\end{array}$ \\
\hline Total & 69 & 75 & 84 & 228 \\
\hline
\end{tabular}

\begin{tabular}{|c|c|c|c|c|}
\hline \multicolumn{5}{|c|}{ Malignant disease } \\
\hline $\begin{array}{l}\text { No without DVT } \\
\text { No }\left({ }^{\prime \prime},\right) \text { with DVT }\end{array}$ & $\stackrel{19}{9}(32)$ & $\begin{aligned} 11 \\
9(45)\end{aligned}$ & 12 & $\begin{array}{l}42 \\
19\end{array}$ \\
\hline Total & 28 & 20 & 13 & 61 \\
\hline Grand total & 97 & 95 & 97 & 289 \\
\hline
\end{tabular}

TABLE III-Percentage incidences of DVT in patients given dextran alone or combined with pneumatic compression and in patients given pneumatic compression alone

\begin{tabular}{|c|c|c|c|c|c|}
\hline Age group (years): & $40-$ & $50-$ & $60-$ & $70-$ & 80 \\
\hline $\begin{array}{l}\text { Dextran alone or in combination } \\
\text { Pneumatic compression alone }\end{array}$ & $\begin{array}{r}8 \cdot 0 \\
19 \cdot 0\end{array}$ & $\begin{array}{l}18 \cdot 0 \\
22 \cdot 0\end{array}$ & $\begin{array}{l}23 \cdot 0 \\
46 \cdot 0\end{array}$ & $\begin{array}{l}29 \cdot 0 \\
55 \cdot 0\end{array}$ & $\begin{array}{l}44 \cdot 0 \\
75 \cdot 0\end{array}$ \\
\hline
\end{tabular}

TABLE IV-Incidences of bleeding complications in the three treatment groups

\begin{tabular}{|c|c|c|c|c|}
\hline & & $\begin{array}{l}\text { Dextran } \\
\text { alone }\end{array}$ & $\underset{\text { alone }}{\text { Compression }}$ & $\begin{array}{l}\text { Dextran and } \\
\text { compression }\end{array}$ \\
\hline $\begin{array}{l}\text { Regimen stopped because of } \\
\text { bleeding during operation } . \\
\text { Wound haematoma } \\
\text { Postoperative bleeding }\end{array}$ & $\begin{array}{l}\ldots \\
\cdots\end{array}$ & $\begin{array}{r}3 \\
12 \\
2\end{array}$ & 2 & $\begin{array}{l}4 \\
6 \\
4\end{array}$ \\
\hline Total & & 17 & 2 & 14 \\
\hline
\end{tabular}

which confirmed the diagnosis. Five had received dextran alone, six pneumatic compression alone, and three both treatments. There was no significant difference in the incidence of pulmonary embolism among the groups. One patient in the combined-treatment group died of a massive pulmonary embolus in a convalescent hospital one month after operation. Her leg scans had given negative results during her stay in hospital.

Effect of other risk factors-Malignant disease was known to be present in $61(21 \%)$ of the 289 patients. The incidences of DVT in those patients with malignant disease given dextran $(32 \%)$ and pneumatic compression alone $(45 \%)$ were greater than the corresponding incidences in patients with benign conditions $(17 \%$ and $36 \%$ ) (table II). In the group given dextran plus pneumatic compression, however, the incidence of DVT in patients with malignant disease $(8 \%)$ was less than that in patients with benign conditions $(20 \%)$. These differences did not reach statistical significance. The presence of varicose veins was a significant risk factor. Twenty-one of the 55 patients with varicose veins $(38 \%$ ) compared with 53 out of 234 without varicose veins $(23 \%)$ developed a DVT $\left(y^{2}=5.07 ; \mathrm{P}<0.05\right)$.

There was no difference in the relative risk between the three regimens. The incidence of DVT increased from $11 \%$ in patients in the fifth decade to $54 \%$ in the ninth decade, confirming that age is a highly significant risk factor. In all age groups the incidence of DVT was lower in the patients given dextran (table III). Fourteen patients $(4.8 \%)$ gave a history of venous thromboembolic disease but the incidence of DVT in this small group was not significantly greater than in those without such a history.

Complications-Anaesthetists were asked to record the total measured blood loss on swabs and suction during each operation. In 18 of all 293 patients $(6 \%)$, who were evenly distributed among the groups, the blood loss was too small to measure, and in $55(19 \%)$ no record was kept. Of the remaining 220 patients ( $75 \%$ ), those given dextran alone lost $10-7500 \mathrm{ml}$ (median $245 \mathrm{ml}$ ), those given compression alone $5-1300 \mathrm{ml}$ (median $175 \mathrm{ml}$ ), and those given dextran plus compression $10-5800 \mathrm{ml}$ (median $130 \mathrm{ml}$ ). Patients whose prophylaxis was stopped because of bleeding were analysed separately. The median was used as a summary statistic because of the skewness in the distribution of blood loss. There was no significant difference in the blood loss between the three treatment groups. In only two cases did the loss exceed $2000 \mathrm{ml}$. Table IV shows the incidences of bleeding complications in the three groups. In seven patients dextran was stopped during the operation because of excessive bleeding. The median blood loss in this group was $285 \mathrm{ml}$ (range 70-590 ml), which was not significantly different from the values for the whole trial. There were, however, significantly more wound haematomas and postoperative bleeding problems in the patients given dextran $\left(\chi^{2}=8.1 ; P<0.01\right)$. The incidence of postoperative haematoma formation was significantly greater in two of the seven units. Eight patients died during the trial, and necropsy was performed on six. In no case did venous thromboembolism contribute to death.

\section{Discussion}

The incidence of DVT in the patients given only peroperative intermittent pneumatic compression $(38 \%)$ was slightly lower than that in the control group ( $43 \%$ ) in our previous multiunit 
trial in a similar patient population. ${ }^{13}$ The incidence in patients receiving dextran $\left(22^{\circ}{ }^{\circ}\right)$ was also similar to that in the dextran group in our previous trial $\left(25^{\circ}{ }_{0}\right)$. The lowest incidence of DVT was observed when dextran and compression were combined $\left(19^{\circ}{ }_{0}\right)$, but this was not significantly different from the effect of dextran alone. Thus the intermittent pneumatic compression as used in this trial appeared to be relatively ineffective in preventing DVT. This contrasts with the results of Sabri et al, ${ }^{*}$ who, in a sequential analysis of 39 patients in whom one leg was compressed and the other acted as a control, found a significantly reduced incidence of DVT in the compressed leg. The reason for our different findings is not clear. In our trial, however, $94^{\prime \prime}{ }^{\prime \prime}$ of the patients underwent major abdominal operations. Possibly in high-risk, elderly patients undergoing abdominal surgery pneumatic compression should be sustained for longer than the duration of the operation. ${ }^{1011}$

The diagnosis of DVT depends on the interpretation of the 1:: I-fibrinogen scans, and differences in criteria for positivity will affect the incidence. Our criterion (a rise of $20^{\circ}{ }^{\circ}$ in activity in relation to the same point on the previous scan or compared with the same point on the other leg $^{6}$ ) was different from that of Sabri et al, who accepted a rise of $15^{\circ}{ }_{1 .}{ }^{*}$ Use of the criterion of Sabri et al would have given us a slightly higher incidence of DVT but would not have altered the relative differences between the treatment groups. We appreciate that by turning a continous variable-namely, percentage increase at a site-into a dichotomous variable some precision in diagnosis might have been lost. Analysis of our scans on the basis of a dichotomous variable, however, permits comparison of our results with the many published series that have been analysed in a similar way.

The incidence of bleeding complications in the patients given dextran was significant. In the seven patients in whom dextran was stopped during the operation there was no objective evidence of increased blood loss in terms of measured suction volumes and weighed swabs, and this could be explained as bias against dextran by the surgeon. Nevertheless, with 24 postoperative bleeding complications in the dextran groups and only two in the pneumatic compression group (table IV) a tendency for abnormal postoperative bleeding to be associated with dextran, when given according to the regimen used here, is undeniable. The regimen was similar to that described by other workers, ${ }^{6}$ i and neither group reported a significant increase in postoperative bleeding complications, although Kline et al ' did mention four patients with troublesome bleeding, all of whom were in the dextran group.

None of the deaths in this trial were attributable to thromboembolism, but the death of one patient one month after surgery from major pulmonary embolism emphasises the importance of late DVT. To our knowledge no trials of prophylaxis have taken account of the fate of patients after discharge from hospital. Our two techniques of prophylaxis gave their maximum effect during and immediately after surgery. They would be unlikely to affect the incidence of late DVT. Some added technique, such as lowdose heparin, would be necessary to cover the small group of patients with prolonged immobility or morbidity.

We thank the consultants in the general surgical units who kindly permitted their patients to be studied, and the anaesthetists who ensured that the prophylaxis was administered and recorded the operative blood loss. The staff of the University Department of Medical Physics, Edinburgh, under Dr P Tothill and Dr J Simpson, carried out the leg scanning helped by junior surgical staff. The British Oxygen Company supplied the venous flow stimulators, and Travenol Limited supplied the dextran 70. Miss I Morrison typed the manuscript.

\section{References}

1 International Multicentre Trial, Lancet, 1975, 2, 45.

2 Williams, H T, Lancet, 1971, 2, 950.

${ }^{3}$ Gordon-Smith, I C, et al, Lancet, 1972, 1, 1133.

4 Nicolaides, A N, et al, Lancet, 1972, 2, 890.

5 Lambie, J M, et al, British Medical fournal, 1970, 2, 144.

${ }^{6}$ Bonnar, J, and Walsh, J, Lancet, 1972, 1, 614.

Kline, A, et al, British Medical fournal, 1975, 2, 109.

${ }^{8}$ Sabri, S, Roberts, V C, and Cotton, L T, British Medical Fournal, 1971, 4, 394.

9 Roberts, V C, and Cotton, L T, British Medical fournal, 1975, 3, 458.

${ }^{10}$ Clark, W B, et al, Lancet, 1974, 2, 5.

${ }^{11}$ Hills, N M, et al, British Medical fournal, 1972, 1, 131.

12 Negus, D, et al, British fournal of Surgery, 1968, 55, 835.

${ }^{13}$ Multi-unit Controlled Trial, Lancet, 1974, 2, 118

(Accepted 30 fanuary 1978)

\title{
Effect of new dopamine-blocking agent (oxiperomide) on drug-induced dyskinesias in Parkinson's disease and spontaneous dyskinesias
}

\author{
P BÉDARD, J D PARKES, C D MARSDEN
}

pyramidal system, and encourage the search for selective dopamine antagonists.

\section{Summary and conclusions}

Oxiperomide, a new dopamine-receptor antagonist, was found to decrease dyskinesias in patients with Parkinson's disease receiving levodopa or other dopamine agonists without necessarily increasing Parkinsonian symptoms. Oxiperomide also decreased spontaneous dyskinesias in patients with tics and chorea, and to a less extent in those with torsion dystonia, without necessarily causing Parkinsonism.

These results provide evidence that more than one population of dopamine receptors exist in the extra-

\section{Introduction}

Abnormal involuntary movements (dyskinesias) are the commonest dose-limiting complications of anti-Parkinsonian treatment with dopamine agonists such as levodopa alone, levodopa plus a selective peripheral dopa-decarboxylase inhibitor, or bromocriptine. Such dyskinesias are believed to result from overstimulation of certain dopaminergic receptors in the corpus striatum. ${ }^{1}$ Attempts to reduce these drug-induced dyskinesias by decreasing the dose of the dopamine agonist or by administering dopamine antagonists have been accompanied by recurrence of Parkinsonian symptoms. ${ }^{23}$ 